\title{
Label, nudge or tax? A review of health policies for risky behaviours
}

\author{
Matteo M. Galizzi \\ Centre for the Study of Incentives in Health, The London School of Economics, UK
}

\begin{abstract}
Significance for public health
Risky behaviours, such as over-eating, smoking, sedentary lives, and excess alcohol drinking are primary drivers of chronic health conditions, premature deaths, and health care spending. Public health decision-makers have dealt with risky behaviours by implementing three clusters of health policies: i) releasing information on health risks and consequences; ii) introducing incentives; and iii) directly intervening in markets, through regulation and taxation. In order to inform current and future health policy-making, the time is ripe to gather rigorous scientific evidence to assess the relative effectiveness of each type of interventions. At the same time it is crucial to highlight the public health approach staying beyond each type of policy on risky behaviours, and to critically consider them within the context of more general health and social policy interventions. Such a critical review lacks at the moment. This work aims at contributing to fill this gap.
\end{abstract}

\begin{abstract}
This work proposes a critical, non systematic, review of the three main lines of health policy interventions to deal with risky behaviours, such as over-eating, smoking, sedentary lives, and excess alcohol drinking, namely: i) the release of information on health risks and consequences; ii) the use of incentives; and iii) direct policy intervention in markets, through regulation and taxation. First, the health and economic impact of the risky behaviours epidemics are briefly described. Then a critical review follows on the evidence existing on the effectiveness of each type of intervention. The review will also highlight the public health approach staying beyond each type of policy on risky behaviours and critically consider them within the context of more general health and social policy interventions.
\end{abstract}

\section{Introduction}

Risky behaviours, such as over-eating, smoking, sedentary lives, and excessive alcohol consumption are major drivers of chronic health conditions, premature deaths, and health care spending. In this work I argue that public health decision-makers have dealt with the current dramatic rise of risky behaviours by implementing three main arms of health policies: i) releasing information on health risks and consequences (label); ii) introducing incentives (nudge); and iii) directly intervening in markets, through regulation and taxation (tax).

In order to contribute to inform health policy-making, in the present work I review and discuss the most rigorous scientific evidence assessing the relative effectiveness of each type of interventions. At the same time, I highlight the public health approach staying beyond each type of policy on risky behaviours, and critically consider them within the context of more general health and social policy interven- tions. The next section provides some figures on the challenges for public health related to the rise of risky behaviours. The next section critically review the main health policies within the health information arm, the incentives' one, or the direct public intervention arm. The last section discusses the potential scope for behavioural health policy and briefly concludes.

\section{The risky behaviours' epidemics}

There is increasing consensus among public health researchers that over-eating, smoking, sedentary lives, and excess alcohol drinking are currently the four big killers in western countries. These behavioural risk factors are in fact known causes of a number of chronic health conditions which, in turn, are primary drivers of premature death, and health care spending. ${ }^{1}$ The dramatic figures related to the four big killers cannot be over-emphasised: according to the World Health Organisation (WHO), as many as 80 million disability-adjusted life years (DALYs) were lost in 2004 in the world in the age group 1559 because of overweight, obesity, high cholesterol, high blood pressure or high blood glucose. ${ }^{2}$ Moreover, 60 million DALYs lost in the same year were attributable to alcohol use, and further 33 million related to tobacco use. Finally, physical inactivity, on its own, accounts for more than 15 million DALYs lost.

Obesity, in particular, has been identified as a global epidemic. According to the WHO, more than a billion adults are overweight worldwide, and 700 million will be clinically obese by $2015 .{ }^{3}$ According to the latest health data by $\mathrm{OECD},{ }^{4}$ the $30.9 \%$ of the adults in the US, the $24.2 \%$ in Mexico, and the $22 \%$ in the UK adults were obese in the early 2000 s, with the overall figures expected to be around one third of the adult population in each country by now. About 320,000 deaths a year are attributed to obesity in Europe,${ }^{5}$ and 30,000 in UK. ${ }^{6}$ The annual direct costs (treating obesity and its consequences) and indirect costs (lost earnings due to premature mortality and attributable sickness) related to obesity are estimated at $£ 3.3-3 .{ }^{7}$ billion in the UK only. ${ }^{7}$

According to the statistics in some recent reports on the obesity epidemics, ${ }^{8-11}$ US citizens have increased their BMI from 1970 to 2000 by $+8.9 \%$ (24.6 to 26.3 ), but obese people (in the $95^{\text {th }}$ percentile tail of distribution) have put on weight much more quickly than average, by $+16.8 \%$ (33.9 to 39.6). The distribution of obesity across population may also be of concern for public policy, since in the US obese subjects have an average age of 45-55 years, while in the UK an adult in the lower income class is $25 \%$ more likely to become obese than in the top income class. In the UK, the only decrease in BMI in the last thirty years concerns young women from the very top-income class. ${ }^{8}$

The impact of the other behavioural risk factors should not be under-estimated either: the total direct and indirect costs related to alcohol consumption amounts to the $2.7 \%$ of the GDP in the US. ${ }^{2}$ The healthcare costs related to tobacco consumption, on the other hand, amount to $\$ 76$ billion in the US, $\$ 14.7$ in Germany and $\$ 2.25$ in the UK. ${ }^{12}$ 


\section{Public health policies for risky behaviours}

Facing such dramatic figures from rising global epidemics, how have the health policy-makers in the western countries reacted insofar? In the present work, I argue that public health policies have typically dealt with the four big killers using three main arms. These are three clusters of public interventions, grounded on three very distinct economic arguments, that can actually be ranked according to the increasing interference with individual decision-making and the market forces within the health sector.

Moving ideally from the less to the more intrusive policy interventions, the typical three clusters have been: i) the release of information on health risks; ii) the use of incentives; iii) the direct public intervention through taxes and regulation. In what follows, I briefly review and critically discuss the main scientific evidence on the effects of each of these arms of health policies for risky behaviours.

\section{Health information}

The less interfering type of policy intervention is the release of information, for instance, on the health risks related to the risky behaviours. It is a minimally invasive public intervention since individuals still have the same set of choices, and are simply given more information to support their free decisions. The implicit assumption underlying this position is that the more information a consumer (a citizen, a patient) has, the better it is. This assumption is one of the traditional assumptions by mainstream, neoclassical, economics, which also postulates a related set of more general assumptions on human behaviour, namely that i) people are indeed fully rational decision-makers, who ii) process all available information; iii) plan ahead their future actions and have rational expectation; iv) compute the trade-offs between (present and future) costs and benefits; v) optimize, that is, find the optimal solution that maximize their own utility based on their underlying preferences, given the set of constraints.

Clearly, such a set of strong assumptions can only bring to the conclusion that public policy interventions should not interfere with individual choices, which are fully rational: for instance, smoking can simply be a rational addiction, and the decisions of people who chose to become obese and thus unhealthy, should be regarded as rational, as the one of people choosing not to invest in their own education, or to work few hours a week and thus remain under-employed. If really the government has to intervene - it is argued - it should implement the least invasive public policy, for instance, by only disclosing information, in order to enable more informed, and thus better, individual decisions. Despite the recent financial and economic crisis has contributed to cast more than one doubt about the ability of the rational expectations model to predict what happens in the real world, this position, which often (at some extent erroneously) goes under the label of Chicago School, is still very influential among academic economists, especially in the US.

In the context of risky health behaviours, the partisans of this position argue that the government should just expose consumers to complete information about the health risks of smoking, eating too many calories, following nutritionally poor or unbalanced diets, drinking too much alcohol, and not doing physical exercise. Once given better information, people should then be left alone to make up their free decisions, and no further interference in individual choices should be tolerated.

In principle, a number of health policies in the OECD countries can be thought to be consistent with this position: for instance, the labels of the type Smoking kills on cigarettes' packages, and the related health information on the risks of smoking; or, generally, the nutritional labelling on the food items, reporting calories, daily recommended amounts and other nutritional information; or the informational campaigns of the type 5-a-day, for the portions of fruits and vegetables; or
2(3) alcohol units a day for the alcoholic drinks for women (men); and in generally the idea of running informational campaigns, distributing leaflets and posters and similar. Of course, I am not so fool to argue that all these informational policies have been actually launched and implemented by a gang of hard-nosed mainstream economists. Rather, what I wish to stress here is that for people sharing their views, health policies to tackle risky behaviours should never go much beyond these type of informational interventions.

From the perspective of an empirical researcher, I feel it is much more useful to directly turn the attention to the available scientific evidence on whether, and at what extent, informational campaigns are effective in reducing risky health behaviours. As a general picture, it is probably fair to say that there is little compelling scientific evidence that health information alone is effective in reducing risky behaviours. At a macro level this is consistent with the observation that, despite informational policies have been around for a while, risky behaviours such as over-eating and obesity, rather than decreasing over time, have been sharply rising as evidently documented above.

Concerning, more specifically, information on healthy eating, the existing evidence is rather mixed. For instance, there are studies ${ }^{13}$ that have evaluated the already mentioned 5-a-day campaign, an informational campaign run in UK between 2002 and 2004 to educate British people to eat at least 5 portions of fruits/vegetables a day, bringing evidence that informational campaign was associated with a $+27 \%$ increase of the purchases of fruits and vegetables with respect to what would have occurred if prices had not changed.* But, even after the 5 a-day info campaign, the lower income families still consume half fruits and vegetables than the richer families and reacted much less sharply $(+20 \% v s+36 \%)$. More generally, a review of the scientific assessments of its effects found that the 5-a-day info campaign raises awareness of the need to consume more fruit and vegetables, but was not associated with significant changes in behaviour. ${ }^{8}$

Little is also known on the effectiveness of nutritional labelling on foods. In general it is useful to keep in mind that, at least in Europe, there are two main schemes for nutritional information, namely the guidelines for daily amounts (GDA) and the traffic lights systems. In essence, GDA provides full nutritional facts, while the signposts only report simplified labels with green, amber, red colours on selected nutritional categories. In Europe there is an ongoing debate on which system should be preferred: for instance, the UE Commission and nutritional experts are in favour of GDA, as they argue that signposts tend to over-simplify the nutrition information. On the other hand, as reported by George Loewenstein, ${ }^{14}$ a typical consumer would probably not disagree with what the US first lady, Michelle Obama, said about the GDA system in march 2010 to the conference of the American Association of Grocery Manufacturers: The last thing I had time to do was to stand in a grocery store aisle squinting at ingredients that I couldn't pronounce to figure out whether something was healthy or not. In the UK the two schemes are voluntary and supermarkets chains choose the one they prefer: for instance, TESCO uses GDA, M\&S used the signposts, while and Waitrose and Sainsbury's use both.

There is little, and mixed, evidence on the effects of GDA and signposts nutritional labels, and in general it refers to the US or the UK. For instance, in the US the Nutritional Labeling and Educating Act (NLEA) labelling system, a variant of the GDA system, has been implemented for nutritional information at a cost in the range of $\$ 166$ billion. An empirical evaluation of the effects of NLEA labels in the US, using a Difference-in-Difference empirical approach, found no impact on obesity rates, except the ones of white women who used the labels. ${ }^{15}$ It concluded that the NLEA system could have possible benefits only for the consumers already motivated to eat more healthy foods and that already use nutritional information on the labels and packages.

*Actually prices did increase in the 2002-2004 for being most vegetables and fruits imported from outside the UK, and that it is important that empirical analysis accounts for it. ${ }^{8}$ 
Similar mixed results have been found for calories labelling in New York City, where the Department of Health passed a legislation mandating that from $1^{\text {st }}$ July 2007 all food establishments with standardised portions (basically, chains of coffee shops and restaurants) have to post calorie information on their menu boards. Two studies by George Loewenstein and colleagues ${ }^{16,17}$ tested whether this information affected food choices by collecting data at three locations (a coffee shop in Manhattan, and two hamburger restaurants of the same chain, one in Manahattan, the other in Brooklyn). Researchers standing outside the restaurants randomly assigned customers to two treatments: in one treatment, they received information about suggested calorie intake per day, in the other calorie intake per meal. They found no impact of the legislation and of either calories recommendation at the coffee shop; no impact of the legislation in the restaurant in Manhattan, while fewer calories were consumed after the legislation in the restaurant in Brooklyn, especially by people that were already on diet. Moreover they found that calories-per-meal recommendation significantly increased the caloric intake of people on diet relative to non-dieters. These results provide mixed evidence that labelling policies can have some limited impact on specific groups of the population, while providing calorie recommendations not only is not effective, but may even have perverse effects.

Similar evidence is available on the GDA-type informational system, that was found to lead to increase in consumption of iron and fibres, but to have no impact on overall intakes of total fat, saturated fat, cholesterol, and no significant impact on obesity rates. ${ }^{8}$ Also concerning signposts the existing evidence suggests that labelling works only for the more motivated and interested consumers, and mostly in terms of avoiding really bad foods (red light), than choosing genuinely healthy food (green light). ${ }^{18+}$

More encouraging evidence about the effectiveness of nutritional labels come from a recent experiment. ${ }^{14}$ About 1200 subjects were recruited for survey study, in exchange for free snacks, and randomly assigned to one of 10 labelling conditions, varying from either no information, or calories information only, or daily intakes references, or information about the minutes to be spent on a treadmill, or the traffic lights rating, or finally, some heuristic cue such as the expected body size associated with the food. In general, the experimental results support the idea that labelling can lead to some decrease in the calories of the chosen snacks. ${ }^{14}$ Not all types of labelling, however, were equally effective. In particular, the effects of numerical information tend to be rarely significant and smaller than the ones from heuristic cues. For instance, significant decrease (that is of $-10 \%$ or larger) in the calories of chosen snacks occur only when numeric information was in terms of minutes on treadmill and percentage of daily snacks calories. Interestingly, the effects was much more significant (-20\% or larger) when labelling used heuristic cues such as traffic lights and expected body size. Moreover, and importantly, no effect in normal weight sample, but significant effect in overweight sample. ${ }^{14}$

More generally, a systematic review ${ }^{19}$ found that both GDA and signposts do not lead to consumers avoiding unhealthy foods, but only to moderate their consumption; and that both labels only trigger local substitution effects, in the sense that consumers switch to healthier options within the same categories, but not radically alter the structure of their diet. Importantly, however, nutritional labels can in principle also have some effects on the producers: manufacturers may change the composition of some foods to obtain more attractive nutritional labels.

Substantially similar results concern the evidence on the informational policies about the risks of smoking or alcohol abuse.
The general message seems to be that people are much more aware of risks, but struggle to change their daily habits, although lots of promising empirical research is currently going on in health economics on the effects of the public bans to smoke in public places, for instance. Also, notice there are researchers who argue that informational policies should not be judged on the ground of effectiveness only. In fact, it is argued, more health information is (socially) beneficial even if it produces no changes in behaviour, since it enables people to choose what they prefer, ${ }^{20}$ an argument which is consistent with the above discussed presumption that more information is always beneficial for making better choices.

Before moving to the second arm of health policies, it may be of interest to describe a recent field experiment, ${ }^{21}$ which provides one of the few direct analysis of the interaction between information provision and behavioural incentives (nudges in the asymmetric paternalism approach proposed by Camerer, Loewenstein and colleagues, ${ }^{22}$ and by the bestseller book by Thaler and Sunstein: ${ }^{23}$ see below and last section for a discussion). Researchers approached customers entering a fastfood sandwich restaurant and offered them a free meal in exchange for the participation to a survey. Customers who agreed to participate were asked to pick a sandwich, and then a side dish and a drink from a provided menu; they then completed the survey; and were finally given a voucher with their order to be passed on to the restaurant. The different treatments interacted the release of caloric information for menu items and of daily calories recommendation, and the manipulation of different nudges on the convenience of the healthy options. Non-financial incentives were given in different treatments to make healthier options more convenient: for instance, in one treatment healthy options were the default choices in the first page of the menu, in another there was an immediate extra effort required to order a less healthy option (opening a sealed packet).

Both calorie information and calorie recommendation were found to decrease calories in ordered foods..$^{21}$ Both the non-financial incentives increased the likelihood to choose sandwich options with lower calories. The default option, however, appeared to also induce a compensatory effect on non-sandwich calories that completely offset the impact of calorie information. ${ }^{\circ}$

\section{Financial incentives}

A more direct form of health policy intervention advocates the use of incentives. Economists believe we respond to incentives, and economics is, at a large extent, exactly the analysis of incentives. It is thus rather natural for economists to believe that, in principle, under appropriate incentives, people may react changing their health behaviours. The fast-growing rise of behavioural and experimental economics has contributed to broaden the analysis of incentives and to base it on rigorous scientific evidence rather than theoretical arguments. Within the economists' community, in fact, the more constructive challenges to the traditional mainstream view currently comes from the field of experimental and behavioural economics, a research camp that is more interested to understand how people actually choose and behave, rather than to speculate on how they should take decisions and actions. In the past thirty-forty years, hundreds of experimental economists, often pooling together with psychologists, neuroscientists, and medical doctors, have generated piles of original data through lab and field experiments, and empirically tested the hypotheses that people are rational decision-makers, plan ahead, rationally trade-off and so on.

In 2002, the experimental approach has been consecrated by the Nobel prize to Daniel Kahneman and Vernon Smith. 
Some of the results of the experimental research by Kahneman and experimental colleagues can perfectly illustrate the Copernican revolution that is expected to slowly reshape economics: thousands of experiments show that we are human beings, and as such, we do make lots of mistakes and errors; we are often unable to make the best choice for us, or sometimes we even do not know what is best for us; we are often let down by too much information and choice; we suffer from risk aversion, loss aversion, myopia, impatience, and overconfidence; we often take decisions and actions that seem more satisfying rather than optimizing.

Concerning health behaviours, behavioural economists have proposed a new approach that is not based on information but on incentives and other nudges. This approach is sometimes called asymmetric paternalism $^{22}$ or libertarian paternalism, ${ }^{23}$ and has two central elements. First, is libertarian in the sense that it intends to shift behaviour in self-interested directions, without questioning the ultimate freedom of choice by individuals. Secondly, is asymmetric or paternalist in the sense that it intends to only help people who decide and behave in a self-destructive way.

The introduction of incentives and nudges is currently of the highest importance across the whole spectrum of public policy interventions, from health and social care, to pensions and financial markets, to crime, the environment and climate change, especially in the UK where the Cabinet Office has recently released the MINDSPACE report drawing insights from behavioural sciences ${ }^{26}$ and has established a Behavioural Insights Team to support policy decisions. Also, in countries such as the US and the UK, where the rise of the above described risky behaviours epidemics has been more dramatic, the public opinion often divides itself in favour or against the political proposal to pay people to quit smoking, to lose weight, to exercise more, or to eat more fruits or vegetables. Broadly speaking, appropriate incentives in health can be designed to induce people to change their health behaviours, either by making healthy activities cheaper (for instance, subsidising healthy foods such as vegetables and fruits, or regular physical exercise); or by limiting unhealthy behaviours (for instance, rewarding the ones who quit smoking, cut alcohol drinks, or lose weight). ${ }^{\S}$ A complete review of the type, role and effects of financial incentives in health is clearly far beyond the scope of this discussion, also because there is quite a lot of work in progress at the moment." Here I will only focus on a discussion and brief review of the incentives related to the four big killers. These incentives usually target subjects in the general population, or in some sub-categories at a higher risk, such as smokers, obese people, pregnant mothers, children. Usually, the targeted behaviours is habitual, as in the case of over-eating, smoking, sedentary lives, alcohol abuse. As mentioned, the intended targeted behaviour may consist in removing an unhealthy behaviour (e.g. quit smoking, cut alcohol drinks, do not eat fats or sugars) or in promoting an healthy behaviour (e.g. eating more fruits or vegetables, making regular physical exercise). Most of the times, of course, the intended objective is a sustained change of behaviours over time, and not just a one-off change.

\footnotetext{
${ }^{\$}$ The scope of introducing incentives in health is much wider, though, and incentives in health can be implemented in different forms according to: Target subjects: subsamples of the general population (consumers, workers, kids, mothers); patients; healthcare professionals (e.g. doctors, nurses); Target behaviours: health behaviours; undertaking medical treatments, screening and diagnostic tests, vaccinations, medical compliance/adherence; outputs, prescriptions, performance; blood and organ donation Characteristics of the behaviour: risky habits (smoking, drinking, over-eating, sedentary lives) versus socially desirable activities (blood and organs donation); repeated vs one-off behaviour; removing unhealthy behaviour versus promoting healthy behaviours; Characteristics of the incentive: cash, vouchers, prizes, deposits, lotteries, for instance.

\#In the UK, for instance, the Wellcome Trust has established and funded with a strategic grant the Centre for the Study of Incentives in Health (CSIH), a joint inter-disciplinary inter-university research centre by Kings' College London, London School of Economics, and Queen Mary University London, which involves psychologists, behavioural and experimental economists, and philosophers and experts in bioethics. A analogous initiative in the US is the Center for Health Incentives and Behavioural Economics (CHIBE) a the University of Pennsylvania. Researchers in these, and other, centres are currently working on original experimental studies and systematic reviews and meta-analyses on the effects of financial incentives.
}

Although all incentives are conditional on observed changes in behaviours, in practice they can take very different forms, including money, non-monetary payments (e.g. goods, vouchers, health-related goods), prizes, lotteries.

Before reviewing the existing evidence, it is worthwhile to point out that, from an empirical economist's perspective, there are at least two main issues related to the use of financial incentives for healthier behaviours. The first, central, question concerns whether financial incentives indeed work. Generally speaking, the effectiveness of incentives can only be tested through randomised controlled experiments, similar to RCTs in medical and pharmacological studies.

In the experimental intervention, subjects are randomly assigned to either a control group (C) with no incentive, or to one, or more, treatment groups (T) where treated subjects are given financial incentives conditional to health behaviours. Behaviour in the field is observed and then compared across the control and treatment groups. Incentives are effective when there are statistically significant differences $(\Delta)$ in observed outcomes between the control and the treatment groups. Moreover, the most reliable studies follow subjects for a sufficiently long period after incentives are removed, and some adopt a so-called Difference-in-Difference design, which consists in comparing the differences over time across $\mathrm{C}$ and $\mathrm{T}$ before and after a natural occurring intervention.

In general, an incentive can be said to be effective if, at the end of the intervention, the difference in the average intended change in behaviour is positive and (statistically) significantly different from zero, that is if $\Delta(\mathrm{T}-\mathrm{C})>0$. Incentives are not effective if the difference is not statistically different from zero, that is if $\Delta(\mathrm{T}-\mathrm{C})=0$.

Of course, one can further disentangle the effects related to effectiveness, for instance analysing the relative effectiveness; or the costeffectiveness of incentives; or, again, their long-term effectiveness, intended as the sustainability of change in behaviour: subjects, in fact, can respond to incentives with one-off changes in behaviours, but fail to sustain the changed behaviours in the long run.

The second main issue with incentives in health is related on whether incentives may crowd out intrinsic motivation. This hypothesis was originally investigated by Richard Titmuss about blood donations ${ }^{27}$ and then further developed by behavioural economists such as Bruno Frey, among others. ${ }^{28}$ Basically, by attaching a price to something that was originally done for free, we may attract some more people to donate blood, but the donors that were already giving blood may react by stopping doing it. They, in fact, may prefer to rather avoid to be seen as donating blood just for money. From this perspective, incentives to donate blood may end up by making blood donations no longer a pro-social activity, and becoming just a market exchange.

The literature on incentives in health discusses about the theoretical possibility that, if you pay people to quit smoking or lose weight, they may react by not doing what originally intended to be targeted by the incentives, as they do not want to be seen as doing it just for money. ${ }^{29}$ In the experimental framework discussed above, evidence from crowding out would be consistent with an average negative change in the targeted behaviour: $\Delta(\mathrm{T}-\mathrm{C})<0$.

There is an increasing number of randomized controlled experiments studying the effects of financial incentives for encouraging quitting smoking, physical exercise, healthier diets, and weight loss. Concerning smoking cessation, a randomised controlled trial paid pregnant women vouchers that were contingent (in the treatment group) or not (in the control group) to quitting smoking, and observed subjects during pregnancy and 12 weeks after vouchers were removed, finding that contingent vouchers were more effective in inducing smoking cessation and that effects were sustained up to 24 weeks post-partum (that is, 12 weeks after end of vouchers). ${ }^{30}$

Another study randomly assigned 179 smokers who were participating to a five sessions program during 8 weeks (where nicotine patches 
were given to participants) to either an incentivised or a control group: in the treatment group subjects were given $\$ 20$ for each session they were participating, plus $\$ 100$ if they actually quitted smoking at the end of the program. ${ }^{31}$ The study looked at both the short-run and the longrun effectiveness of incentives. In the short-run, by looking at 75 days after the end of the program, it found significantly higher rates of enrolment in, and completion of, the program, and also of quitting rates, in the treatment group, suggesting that incentives worked. Effects, however, were not significantly different in the long-run: in fact, 6 months after the end of the program, quitting rates were not significantly different across the treatment and the control groups. Thus financial incentives were only effective in the short run, although they did not crowd-out intrinsic motivation either.

Concerning physical exercise, a study randomly assigned university students to three groups: either a control group (C) where they were given handouts explaining the health benefits of regular physical exercise; or a low incentive group (L), where they received $\$ 25$ if they attended the gym at least once a week; or finally a high incentive group $(\mathrm{H})$, where they received $\$ 100$ if they attended the gym at least 8 times a month. ${ }^{32}$ Subjects were observed during all the intervention and also up to seven weeks after the incentives were removed. The study found that post-intervention attendance of gym was significantly higher in treatment $\mathrm{H}$ than in groups $\mathrm{C}$ and $\mathrm{L}$. The main conclusion of significantly higher attendance the high incentive group was confirmed by a second study, where they randomize students across 3 groups: in all groups subjects were given handouts and paid $\$ 75$ in advance, and, while in the control group (C') there was no further requirement, in one treatment group (L') subjects were required to attend gym once in a week, and in the other $\left(\mathrm{H}^{\prime}\right)$ they were required to attend the gym 8 times a month. Motivated by the fact, that the higher attendance was mostly driven by subjects who before were not regular gym attendees, the authors interpret the results in terms of positive habit formation, thus ruling out the possibility that financial incentives may crowd-out intrinsic motivation. ${ }^{32}$

Concerning incentives for healthy diets, a study on children first elicited children's liking of six vegetables before intervention. ${ }^{33} \mathrm{~A}$ total of 472 children were then randomly assigned to four experimental conditions: a control group, a group where children were repeatedly exposed (10-12 weeks) to eating vegetables, and other two treatments, where, together with the exposure, children received either a tangible reward, or a social reward (public appraisal) if eating more vegetables. The study re-assessed the likings of the vegetables and also directly observed the vegetables intakes during all the intervention, and up to three months after, and found that both liking and intakes increased in the groups with exposure compared to the control group, and even more sharply in the sessions with exposure and rewards. Interestingly, both the effects on intakes and liking persisted after 1 and 3 months, providing direct evidence that financial incentives to improve healthy diets are unlikely to crowd-out intrinsic motivation in children. Quite at the contrary, if the subjects' intrinsic motivation can be signalled by the children's liking of the vegetables, the experiment provides direct evidence that financial incentives can crowd-in intrinsic motivation to genuinely appreciate vegetables more.

There are also some experiments that have looked at financial incentives for weight loss. The earlier literature, for instance, have run several randomised control trials where they typically found that although incentivized groups had quicker and significantly larger weight losses than in the control group, substantial amounts of weight was regained three months after the end of the incentive. ${ }^{34,35}$ More recently, one study randomly assigned obese patients to either a treatment with steady payment, or with front- or back-loaded incentives and monitored their weight loss after three and six months. ${ }^{36}$ The study found that, after three months subjects in the front loaded incentive group lose significantly much more weight than in the other groups, but also that that were no significant difference in the weight loss across different incentives after 6 months. The evidence from these experiments suggest that financial incentives for weight loss may hardly sustainable behavioural changes in the long term, which is consistent with the fact that maintaining weight loss may be the key problem for obese subjects.

The most encouraging experimental evidence is the one provided by Volpp, Loewenstein and colleagues at CHIBE. They designed a randomised controlled experiment to study supercharged incentives to lose weight using several insights from behavioural economics research. ${ }^{37}$ Their study randomly assigned 57 obese men to three groups and followed them during 16 weeks of intervention, plus a six-months followup period. The three groups were a control group (C) where subjects took part in a weight-monitoring program with monthly weigh-ins: they had to weigh every morning before eating or drinking and call a number to report their weight. Also, every end of the month, all subjects had to weigh on a clinical scale to see if they were below their weight target. The other group was a deposit contract group (D): subjects could contribute between $\$ 0.01-3.00$ each day of month. Their amount was matched 1 to 1 from the experimenters, who also added $\$ 3$ per day, so that subjects in the group could gain up to $\$ 252$ a month after the matching. The deposit, however, was only refundable if, at the end of the month, they met, or were below, the assigned target for the weight loss, in which case the deposited money was actually paid out. The last group was a lottery treatment (L), where subjects were eligible for a daily lottery only if they reported a weight at, or below, their goal. The lottery was designed in such a way that it paid frequently small payoffs $(\$ 10)$ and infrequently large payoffs (\$100). Another key ingredient of this treatment was the introduction of punctual feedback to subjects: every day, right after their reports, subjects received text messages on their mobile phones that informed them about how much money they have earned that day in case they have achieved the target, and, if unsuccessful, about how much they would have earned if they had reached target. The final element was that subjects successful to lose weight at the end of the 16 weeks were followed up for 6 months after end of incentives.

The main results of the experiment are the following. First, significantly higher weight losses and higher success rates after 16 weeks were observed for subjects in treatments $\mathrm{D}$ and $\mathrm{L}$ than in the $\mathrm{C}$ group. Concerning longer term effects, subjects were observed 7 months after the end of the incentives, and, although there were no significant differences in weight loss from the end of the intervention across subjects in the C, D and L groups, subjects in groups D and L still weight significantly less than at the beginning of the program. This experiment shows that, even when incentives were removed, subjects did not regain weight, and that the concern about crowding-out of intrinsic motivation does not seem to be motivated by direct evidence.

The experiment by Volpp, Loewenstein and colleagues at CHIBE remains the only one providing unambiguous effects that financial incentives may potentially work also for inducing significant weight loss among obese subjects. Compared to previous and alternative tests of the effectiveness of incentives for weight loss, the experiment by Volpp, Loewenstein and colleagues seems the one to have devoted the higher attention to a careful design of supercharged incentives in light of the most recent insights from behavioural sciences. Actually, consistently with the authors' specific approach to asymmetric paternalism (see also below) the design is deliberately and firmly grounded on previous evidence from behavioural experiments. For instance, the idea of providing text messages and feedback every day immediately after weighing on the scale and reporting the weigh was motivated by the evidence that even small rewards and punishment have great incentive value. Also, in the same lottery treatment, the choice of frequent small payoffs and infrequent large payoffs was motivated by the evidence that people is less risk averse and more attracted by large stakes. Moreover, 
the idea of sending text messages to subjects who did not achieve the target with feedback on what they could have gained if successful, was motivated by the evidence that the desire to avoid (anticipated) regret drives decisions under risk. Finally, the deposit contract in which the cumulated money could be lost if subjects were unsuccessful in reaching the weight loss target was based on the idea of loss aversion, namely that we react more strongly to losses than to gains of the same amount. The main message by the paper is that supercharged incentives based on scientific evidence from behavioural sciences can work also in promoting weight loss, especially in the short term. All in all, the evidence from existing experiments on the use of incentives to trigger behavioural changes and to contrast the rise in risky behaviours, seems to suggest that there is a large potential scope for experimental and behavioural sciences to design incentive schemes and to provide scientific evidence to inform effective health policies.

\section{Taxation and other direct public interventions}

The call for more humble and realistic assumptions about the real nature of human decision-making and behaviour inspired by the direct experimental evidence from behavioural economics leaves the door open to direct policy interventions, which are by definition redundant and harmful under the mainstream presumption that people always make perfectly rational decisions and actions. This has led some of the most distinguished behavioural scientists to call for further forms of policy interventions that go beyond the use of financial incentives and nudges, and that potentially involve more coordinated and direct interventions in markets to deal more effectively with risky health behaviours. George Loewenstein, for instance, a leading pioneer of behavioural economics who has extensively worked at the interface between economics, psychology and neuroscience, has argued that insurgence of obesity is also related to a serious misalignment of prices of foods in markets. He has recently argued that market prices may be essentially wrong in the food sector: ${ }^{14}$ in particular, food prices are misaligned because of both externalities and what he calls internalities. In the economists' jargon, externalities are costs that people impose on others but for which they do not take into account in their private decisions. Basically, externalities in the food markets are due to the fact that the prices people pay for unhealthy food (e.g. energy dense foods and drinks, food high in saturated fats) do not reflect the true direct and indirect costs to society. From an economic perspective there are arguments to sustain that food prices are too low. For instance, prices of foods have decreased in real terms in 1975-2005, that is, that prices of other goods have increased more. ${ }^{8}$ Moreover, at least in the US, prices of carbonated drinks, sugars and fats have decreased in real terms in 1975-2005, and have also decreased by a larger extent than prices of other foods (vegetables for instance). ${ }^{8}$ This evidence suggests that the relative prices of energy dense foods have dropped, while the relative (and absolute) prices of healthy foods have risen. Just as a possible example, while the real price of fruits and vegetables rose by $+17 \%$ in 1997-2003, the real price of 2-liter bottle of Coke fell by $-35 \%$ in 1990 2007. The above trends have made cheaper and cheaper over time highcalories-for-nutrient foods, as also suggested by Drewnowski, a public health researcher in Washington who argues that what really matters is, in fact, the price for calories. For instance, a direct measurement of prices for calorie in low- and high-calories-for-nutrient foods available in US supermarkets found that carrots cost more than 5 times per calorie than chips, and that orange juice cost more than 5 times per calorie than Coke, and that that price per calorie of vegetable/fruit has increased over time much more (+40\%) than snacks and other energy dense foods (-23\%). ${ }^{38,39}$ There is also who argues that the US agricultural public policy can be partly responsible for the relative sharper decrease in the costs of energy dense nutrients, since the US government used to subsidise soy and corn production for instance. ${ }^{9}$ Evidence that high-calories-for-nutrient foods are less (and becoming less and less) expensive than low-calories-for-nutrient in terms of price per calorie is not confined to US, though: for instance, vegetables were found to cost more than 3 times than candies in supermarkets also in Israel. ${ }^{40}$ If prices of energy dense foods are wrong in the sense they are too low, the food industry does not directly bear the higher external costs to society of health consequences of unhealthy foods. This motivates the introduction of a typical public economics instruments to deal with externalities, namely taxes. Taxes are indeed the most typical example of health policy intervention within to the third cluster of more direct policies to deal with risky behaviours. Taxes, in fact, by changing the market prices, directly interfere with the market mechanisms and affect consumers' choices and decisions. Examples of taxes on risky behaviours are already present in most developed countries, and, for instance, are usually levied on cigarettes and alcoholic drinks. ${ }^{* * *}$ Aiming to a similar goal to correct externalities, analogous taxes are levied on the use of oil- and carbon-based energy resources (e.g. carbon tax). The correction of an externality is in fact the main economic argument beyond the discussion of introducing taxes on foods containing high amounts of fats, or saturated fats (such as the so called fat tax), or of sugars (for instance, the soda tax on sweet drinks). Few economic studies have simulated the likely effects of possible fat taxes. For instance, it has been calculated that, in the US, an increase in VAT up to $17.5 \%$ on fat foods can reduce ischemic risks of $1.8-2.6 \%$ with more a 1000 lives saved a year. ${ }^{41} \mathrm{~A}$ simulation of the introduction of fat tax in the UK based on actual calories consumption, found that $2 \%$ of poorest consumers would pay 7 times as much the proportion of their income as the $2 \%$ richest consumers. ${ }^{42}$ It has also been calculated that a tax proportional to fat content can reduce fat intake of $1 \%$, and that burden on poor consumers would be 10 times higher. ${ }^{43}$ Some of the advocates of more direct health policy interventions to deal with the rise of risky behaviours also praise for a more systematic and integrated set of health policies to accompany the introduction of, say, a fat tax. For instance, Loewenstein argues that health policy should accompany the introduction of a tax on production and sale of unhealthy foods to the subsidization of healthy foods (e.g. vegetables, fruit); a mandatory progressive pricing of junk foods (for instance in terms of calories) to stop supersizing by fast food and supermarkets; and actions aiming at lowering the cost of exercise (for instance, more bike paths, walking children to school, discourage the use of cars, subsidize gym member, or even public transports). ${ }^{14}$

\section{Conclusions}

\section{From risky behaviours to behavioural health policy}

As I discussed above, prices may be misaligned also because of internalities. Internalities can be defined as the costs that people impose on themselves but that they do not (sufficiently) take into account in their decisions. ${ }^{14}$ Basically, the prices that people pay do not reflect the true costs to themselves. This is an area which is central to the research agenda of behavioural economists such as George Loewenstein: why would people fail to internalize costs to themselves? Experimental evidence from Loewenstein and other behavioural economists suggest that this may be due a variety of reasons related to how people decide and behave in the real world, including the lack of information, the mis-perception of risks, the lack of self-control, the existence of present-biased preferences. These behavioural factors and internalities are deeply rooted attitudes in human beings and it is rather unlikely that they can be simply removed by information and, in many health contexts, perhaps even by simple financial incentives.

**Even though in these cases the public health motivation is confounded by the fact that, from a public economics perspective, it is optimal to tax those goods for their relatively low price elasticity. 
This calls back for a better understanding of the behavioural determinants of health risky behaviours. Once we understand the deeply rooted determinants of health behaviours, we can use them to help people to be aware of, and possibly solve, internalities. This is indeed the essence of the above mentioned specific approach to asymmetric paternalism that Loewenstein, Volpp and colleagues are proposing: using decision errors that normally hurt people to instead help them. ${ }^{44}$ Although relatively new, this approach of supercharging incentives and nudges has already prove to be largely effective. Still, more remains to be done by experimental and behavioural scientists who wish to inform the design of more effective health policies to curb the dramatic burden of risky behaviours.

Correspondence: Dr. Matteo M. Galizzi, Centre for the Study of Incentives in Health, LSE Health, G09 Cowdray House, London School of Economics and Political Science, Houghton Street, WC2A 2AE London, UK.

Tel. +44.20.79555386 - Fax: +44.20.79556803.

E-mail: m.m.galizzi@lse.ac.uk

Key words: Behavioural health economics; incentives in health; fat tax Acknowledgements: the author acknowledges discussions on public health policies for risky behaviours and the use of financial incentives in health with the researchers and scientific advisors at the Centre for the Study of Incentives in Health (CSIH), in particular with Paul Dolan, Richard Ashcroft, Theresa Marteau, Marianne Promberger, and George Loewenstein. The author is also very grateful to Umberto Gelatti, Rosella Levaggi and Marisa Miraldo for discussions, suggestions and encouragement.

Conflict of interest: the author report no potential conflict of interest.

Received for publication: 1 December 2011.

Accepted for publication: 27 December 2011

CCopyright M.M. Galizzi, 2011

Licensee PAGEPress, Italy

Journal of Public Health Research 2012; 1:e5

doi:10.4081/jphr.2012.e5

This work is licensed under a Creative Commons Attribution NonCommercial 3.0 License (CC BY-NC 3.0).

\section{References}

1. WHO. Preventing chronic diseases: a vital investment. 2005. Available from www.who.int

2. WHO. Nutrition, physical activity and the prevention of obesity. Policy developments in the WHO European Region, 2007. Available from www.who.int

3. WHO. Global Status Report on Alcohol and Health, 2007. Available from: www.who.int

4. OECD. Health Data 2010. Available from: www.oecd.org

5. UK Government's Foresight Programme Project. The tackling obesities: future choices project 2007. Available from: www.foresight. gov.uk

6. House of Commons. Obesity, Third report of Session 2003-04. Vol. $1,2004$.

7. Morgan E, Dent M. The economic burden of obesity. 2010, Oxford, National Obesity Observatory, National Health Service. Available from: www.noo.org.uk

8. Mazzocchi M, Traill BW, Shogren JF. Fat economics: nutrition, health and economic policy. Oxford University Press, Oxford, UK, 2009.

9. Kessler DA. The end of overeating. Rodale Ed., New York, NY, USA, 2009.

10. Sassi F. Obesity and the economics of prevention: fit not fat. OECD
Publ., Paris, France, 2010.

11. Finkelstein EA, Ruhm CJ, Kosa KM. Economic causes and consequences of obesity. Ann Rev Public Health 2004;26:239-57.

12. WHO. World Tobacco Atlas Report 2006. Available from: www.who.int

13. Halpern D, Bates C, Beales G, Heathfield A. Personal responsibility and changing behaviour: the state of knowledge and its implications for public policy. 2004, Cabinet Office, Prime Minister's Strategy Unit, London, UK.

14. Loewenstein G. The price is wrong. Slides presentation for the opening talk at the USDA meeting on behavioural economics and obesity, 2010. Available from: http://www.hss.cmu.edu/departments/sds/media/pdfs/loewenstein/loewenstein.pps

15. Variyam J, Cawley J. Nutritional labels and obesity. 2006, NBER working paper W11956.

16. Downs JS, Loewenstein G, Wisdom J. Strategies for promoting healthier food choices. Amn Econ Rev 2009;99:159-64.

17. Wisdom J, Downs JS, Loewenstein G, Wansink B. Calorie posting in New York City: the effect of point-of-purchase information on food choice. Presented at the annual Meet. of the Society for Judgment and Decision Making, November 21-23, 2009. Boston, MA, USA.

18. Fox J, Hayes D, Shogren J. Consumer preferences for food irradiation: how favourable and unfavourable descriptions affect preferences for irradiated pork in experimental auctions. J Risk Uncertainty 2002;24:75-95.

19. Grunert KG, Wills JM. A review of European research on consumer response to nutrition information on food labels. J Public Health 2007;15:385-99.

20. Teisl MF, Bockstael NE, Levy A. Measuring the welfare effects of nutrition information. Am J Agr Econ 2001;83:133-49.

21. Wisdom J, Downs JS, Loewenstein G. Promoting healthy choices: information vs. convenience. American Economic Journal: Applied Economics 2010;2:164-178.

22. Camerer C, Issacharoff S, Loewenstein G, et al. Regulation for conservatives: behavioural economics and the case for asymmetric paternalism. University of Pennsylvania Law Review 2003;151:10144.

23. Thaler RH, Sunstein C. Nudge: improving decisions about health, wealth and happyness. 2008, Yale University Press, New Haven, CT, USA.

24. Epstein LH, Dearing KK, Roba LG, Finkelstein E. The Influence of taxes and subsidies on energy purchased in an experimental purchasing study. Psychol Sci 2010;21:406-14

25. Dolan P, Galizzi MM. Because I'm worth it: experimental evidence on the spill-over effects of incentives. Centre for the Study of Incentives in Health (in progress).

26. Dolan P, Hallsworth M, Halpern D, et al. MINDSPACE: Influencing behaviour through public policy. 2010, Cabinet Office and Institute for Government, London, UK.

27. Titmuss RM. The gift relationship-From human blood to social policy. 1970, Allen and Unwin, London, UK.

28. Frey B, Jegen W. Motivation crowding theory. J Econc Surv 2001;15:590-611.

29. Marteau TM, Ashcroft RE, Oliver A. Using financial incentives to achieve healthy behaviour. BMJ 2009;338:b1415.

30. Higgins ST, Heil SH, Solomon LJ, et al. A pilot study on voucherbased incentives to promote abstinence from cigarette smoking during pregnancy and postpartum. Nicotine Tob Res 2004;6:101520.

31. Volpp K, Levy AG, Ash DA, et al. (2006): A randomized controlled trial of financial incentives for smoking cessation, cancer epidemiology. Biomark Preven 2006;15:12-18.

32. Charness G, Gneezy U. Incentives to exercise. Econometrica 
2009;77:909-31.

33. Cooke LJ, Chambers LC, Anez EV, et al. Eating for pleasure or profit: the effects of incentives on children's enjoyment of vegetables. Psychol Sci 2011;22:190-6.

34. Jeffery RW, Thompson PD, Wing RR. Effects on weight reduction of strong monetary contracts for calorie restriction or weight loss. Behav Res Ther 1978;16:363-9.

35. Jeffery RW, Bjornson-Benson WM, Kurth CL, Johnson SL. Effectiveness of monetary contracts with two repayment schedules of weight reduction in men and women from self-referred and population samples. Behav Ther. 1984;15:273-9.

36. Finkelstein EA, Linnan LA, Tate DF, Birke BE. A pilot study testing the effect of different levels of financial incentives on weight loss among overweight employees. J Occup Environ Med 2007;49:961-9.

37. Volpp K, John LK, Troxel AB, et al. Financial incentive-based approaches for weight loss. JAMA 2008;300:2631-7.
38. Drewnowski A. Fat and sugar: an economic analysis. J Nutr 2003;133:838-40.

39. Drewnowski A, Specter SE. Poverty and obesity: the role of energy density and energy costs. Am J Clin Nutri 2004;79:6-16.

40. Gandal N, Shabelansky A. Obesity and price sensitivity at the supermarket. Forum Health Econ Policy 2010;13:Article 9.

41. Marshall T. Exploring a fiscal food policy: the case of diet and ischaemic heart disease. BMJ 2000;320:301-4.

42. Leicester A, Windmeijer F. The "fat tax": economic incentives to reduce obesity. 2004, IFS Briefing Note 49, London, UK.

43. Chouinard HH, Davis DE, LaFrance JT, Perloff JM. Fat taxes: big money for small change. forum Health Econ Policy 2007;10:Article 2 .

44. Loewenstein G, Troyen B, Volpp K. Asymmetric paternalism to improve health behaviors. JAMA 2007;298:2415-17. 